\title{
Mujer, maternidad y familia: las editoras de prensa y su influencia en la construcción del discurso femenino en Chile a finales del siglo XIX
}

Woman, maternity and family: the press editors and their influence on the construction of women's discourse in Chile at the end of the 19th century

\author{
Claudia Montero*
}

Resumen: Este trabajo analiza la acción de las editoras como generadoras de discursos sobre mujer, maternidad y familia, en el primer período de la historia de la prensa de y para mujeres en Chile (1850-1890). Se plantea una definición de editora, se analiza un corpus de tres publicaciones para dar cuenta que las editoras construyeron un espacio de poder para disputar un lugar en la esfera pública, a través de un dispositivo que le permitió tomar decisiones para articular discursos políticos que hablan a través de contenidos, formatos y el diseño del medio de prensa.

Palabras clave: Editora, derechos de la mujer, historia de la prensa, historia de las mujeres, Chile, siglo XIX

\begin{abstract}
This paper analyzes the action of women editors in Chile, through their discourses about woman, maternity and family in the first period of woman periodical press history (1850-1890. A definition of woman editor is presented, as well a corpus of three publications are analyzed. The aim is to show how woman editors constructed a space of power for themselves in order to dispute a place in public sphere. This will have done through a device which allowed them take decisions to articulate politic discourses. All of them expressed through contents, formats and outline of a press media.
\end{abstract}

Keywords: Woman editor, woman's rights advocacy, history of press, history of women, Chile, 19th Century

Recibido: 4 enero 2019 Aceptado: 8 mayo 2019

* Chilena, historiadora, Profesora Adjunta Instituto de Historia y Ciencias Sociales Universidad de Valparaíso. Trabajo que forma parte al proyecto Fondecyt Iniciación n¹1160361 (2016-2918). 


\section{Introducción}

Este trabajo presenta la acción de mujeres pioneras en la prensa en Chile a fin del siglo XIX. Específicamente recoge la actividad de las editoras: es decir de aquellas mujeres que a pesar de la restricción de las normas de género que les impedía alzar la voz públicamente, traspasaron los límites y desarrollaron productos editoriales que influyeron en la conformación del espacio público. El objetivo es revisar los contenidos publicados por las editoras referidos a los temas de mujer, maternidad y familia.

$\mathrm{El}$ argumento de este trabajo es que las editoras, desde un lugar que construyeron para sí mismas, intervinieron en la discusión sobre el rol de las mujeres en la sociedad a través de la selección de contenidos y su circulación a través de publicaciones periódicas.

El momento que se plantea es fundamental para la conformación del espacio público ya que se dan las transformaciones de la modernización. Entre ellas la emergencia de mujeres como intelectuales, escritoras, traductoras, antologistas, críticas y redactoras. En este trabajo, iluminamos una nueva acción: la de editora. Una función muy poco estudiada en América Latina, por lo tanto, se desconoce la influencia que pudieron tener estas mujeres en la generación de reflexiones como la conformación de la familia, la labor de los sexo-géneros en ella y particularmente el rol de las mujeres.

En las últimas décadas se ha realizado un trabajo que ha dado cuenta de las dificultades de este proceso en que las mujeres pasaron de lectoras a escritoras y, por lo tanto, generadoras de ideas y pensamiento. Este trabajo se desarrolla siguiendo la línea de la teoría feminista para explicar éstos fenómenos.

Algunas preguntas que estimulan este trabajo se hacen en el contexto de comprender la compleja relación de las mujeres con el espacio público ¿cómo se piensan a ellas mismas y su rol en la sociedad? ¿cómo refuerzan, discuten o tensan los ideales en torno a lo femenino o lo que debe ser una mujer en un lugar determinado? ¿cómo desde un lugar de poder (la edición), que es autoconstruido y vulnerable dadas las normas de género, reproducen o cuestionan esos ideales? ¿cómo las decisiones que toman desde ese lugar podrían influir en la construcción de discursos políticos con contenido de género?

Se analizan tres medios correspondientes a prensa de y para mujeres: El Eco de las señoras de Santiago (1865), La Brisa de Chile (1876) y La Familia (1891-1894). Los tres forman parte del primer período de la historia de la prensa de mujeres "Las Pioneras" y representan distintos tipos de medios': El Eco es un periódico político, la Brisa de Chile es una revista literaria y La Familia una revista magazinesca comercial. Se trabajó con los índices de las revistas publicados en www.prensademujeres.cl, a partir de los cuales se realizó un análisis de los títulos de los artículos. Una visión panorámica de los títulos permitió ver la presencia de los temas en la conformación de las publicaciones. Es decir, presencia de secciones regulares referidas a los temas o recurrencia de artículos en secciones irregulares. Además, se seleccionaron artículos que abordan contenidos referidos al rol de las mujeres, maternidad y familia, los que se analizaron a través de análisis crítico del discurso para lograr las conclusiones que se presentan.

\section{Elementos para comprender la acción editorial femenina en el siglo XIX}

Una primera cuestión a considerar es el espacio público en relación con el concepto de género. Esto permite comprender el lugar de las mujeres expresando opinión utilizando la prensa, lo que considerando el contexto epocal las pone en un lugar de transgresión. Siguiendo los trabajos críticos a la propuesta de Habermas ${ }^{2}$ que excluye del espacio público a sujetos como las mujeres, ya que no cumplirían con los requisitos de ingreso para una discusión entre iguales porque no son consideradas como tales ${ }^{3}$,

\footnotetext{
${ }_{1}^{1}$ Montero, Claudia. Y También bicieron periódicos... Cien años de prensa de mijeres en Chile 1850-1950. Santiago, Hueders, 2018.

2 Habermas, Jurgen. Historia y Crítica de la opinión pública. Barcelona, GG, 1981.

${ }^{3}$ Landes, Joan. Women and The Public Sphere in the Age if the French Revolution. New York: Cornell University Press, 1988.
} 
se plantea que las mujeres conformarían un contra-público ${ }^{4}$ Estas ideas planteadas por Fraser han sido útiles para comprender otras prensas no hegemónicas como la prensa obrera del Rio de la Plata que estudia Mirta Lobato ${ }^{5}$. Estos planteamientos permiten desmitificar la idea de espacio público como un lugar utópico, ya que sería más bien un lugar excluyente y masculinista. Por lo tanto, la acción de mujeres y otros excluidos abre el concepto y lo visibiliza como un espacio de interacción discursiva, donde a quienes se les ha desvalorizado su aporte, generan contra-discursos que permiten formular otras interpretaciones sobre ellos mismos, sus intereses e identidades.

Incorporando los aportes sobre el concepto de género de Scott tanto en su texto fundacional del año $1986^{6}$ como los del año $2010^{7}$, podemos complementar la lectura sobre la relación de las mujeres y el espacio público, en particular acerca de la editoras en el contexto de fin del siglo XIX en Chile. Esto porque los planteamientos de Scott implican utilizar la categoría de género para, por una parte, comprender las relaciones sociales basadas en la diferencia sexual, y por otra, el lugar en el que se articula el poder. De tal forma, podemos observar cómo el género se traduce en los símbolos culturales, normas, la acción de las instituciones y la conformación de las identidades subjetivas. También, plantea la necesidad de indagar los elementos que permiten que las diferencias se mantengan.

El análisis de las editoras se alinea con las ideas de Scott al comprender que las relaciones de género se construyen de acuerdo con las condiciones sociales, políticas, económicas y culturales y alejarnos de concepciones binarias en relación con las prácticas de hombres y mujeres, centrando el análisis en las relaciones de poder. Las prácticas de edición desarrolladas por mujeres dan cuenta de la complejidad de la relación de las mujeres con el espacio público. Por una parte, están las dificultades puestas por normas de género que impedían la emisión de opinión pública en tanto mujeres. Por otra, la transgresión de la norma por parte de las mujeres al desarrollar estrategias para hacer efectiva la voz y constituirse en sujetos sociales. Todo en un contexto de transformación modernizadora que en tanto su esencia contradictoria ${ }^{8}$ permite las condiciones de posibilidad para la acción femenina a la vez que dicta normas, muchas de ellas encarnadas en leyes, que impiden esa misma acción.

Así, la acción editorial da cuenta del poder en las relaciones de género que tiene imprenta: la exclusión, la transgresión y el lugar que las mujeres construyen, que tiene mucho de afirmación y de vulnerabilidad. Cuestiones que se traducen en las tensiones evidentes en las decisiones editoriales de las editoras de fin del siglo XIX en Chile.

La acción editorial femenina en Chile se da junto con la irrupción de nuevos sujetos sociales que se tomaron la palabra en la emergencia de la ciudad modernizada (1880-1920) que describe Ángel Rama9. Estos intelectuales desafiaron al poder y combatieron los privilegios de la ciudad letrada para dar paso a nuevos grupos sociales ${ }^{10}$. Las editoras representaron ese mismo desafío, sumando el riesgo de perder el derecho al habla, al momento mismo de tomárselo, ya que transgredían una norma. La acción contradictoria de estas editoras permite pensarlas bajo la perspectiva de Irigaray ${ }^{11}$, ya que la edición puede ser una forma de lenguaje y por tanto es una forma de expresión.

\footnotetext{
${ }^{4}$ Fraser, Nancy. "Repensando la esfera pública: una contribución a la crítica de la democracia actualmente existente." In Habermas and the Public Sphere, by Craig Calhoun. Cambridge, Massachussets, MIT Press, 1992.

5 Lobato, Mirta. La prensa obrera. Buenos Aires y Montevideo 1890-1958. Buenos Aires, Edhasa, 2009.

${ }^{6}$ Scott, Joan. "El Género: una categoría útil para el análisis histórico." In El Género: la construcción cultural de la diferencia sexual, by Marta Lamas. México D.F, UNAM, 1996.

7 Scott, Joan. "Género: ¿Todavía una categoría útil para el análisis?”. La Manzana de la Discordia, [S.1.], v. 6, n. 1, p. 95-101, mar. 2016.

8 Berman, Marshall. "Brindis por la modernidad." En El debate Modernidad/Posmodernidad, by Nicolás Casullo, 67-91. El Cielo por asalto, 1994.

${ }_{9}$ Rama, Ángel. La ciudad letrada, Montevideo, Arca, 1998, pp.62.

10 Ibidem

${ }^{11}$ Luce Irigaray, El cuerpo a cuerpo con la madre, Barcelona: Lasal, 1985.
} 
La idea de la edición como lenguaje cobra sentido en el momento de transformación que plantea Rama, ya que se daba cuerpo a una gramática propia para Latinoamérica. Ella articuló orden y dignidad lingüística que reconoció la polifonía "con potencia democratizadora, gesto clave para la legitimación del espacio letrado tensionado y múltiple en su heterogeneidad"12. Con ello se abrió la norma letrada a sujetos antes excluidos entre los que se cuentan las mujeres.

La definición de editora que proponemos es amplia. Abarca cualquier relación con el mundo de producción de medios de prensa: dueña de imprenta de medios, dueña de periódico o revista, fundadora, directora o editora en términos de quien decide qué contenidos se incluyen en una publicación periódica. Por lo tanto, el concepto clave es el de decisión frente a un producto editorial. La amplitud de la definición nos permite dar cuenta de los lugares desde donde se toman decisiones al momento de publicar un medio. Concebir la acción de las mujeres editoras de esta forma tiene sentido al considerar las normas de género de la época. Éstas limitaban la autorización de las mujeres como intelectuales y sujetos de letra. Además, en el contexto de modernización, que introdujo cambios en distintas dimensiones, las mujeres buscaron formas diversas para deslizarse en los intersticios y emitir su voz. Un ejemplo lo ha entregado Darcie Doll ${ }^{13}$ quien habla de los salones del XIX como una forma de inserción de la intelectualidad femenina que no representaba una ruptura. La autora plantea éstos espacios como prácticas intermedias, lo que nos da pie para preguntarnos si el ser editora podría ser comprendido de la misma forma. Es decir, la editora como una forma de inserción consentida. En tanto estrategia para emitir opinión la acción como editora es plástica, se configura y transforma de acuerdo a los objetivos que se tenga al momento de asumir la función frente a un medio.

Según Rama, la letra fue una palanca de ascenso social ${ }^{14}$, por lo tanto, permitió a los nuevos intelectuales encontrar un lugar a través de ella. Esta oportunidad la tomaron las mujeres profesionales de las letras, quienes en tanto formaban parte de estos intelectuales, poseían una nueva sensibilidad, con la que veían los procesos sociales desde nuevos enfoques, que les permitían ver nuevos significados para los fenómenos sociales ${ }^{15}$. Las editoras, al sumar su experiencia de género, eran capaces de develar una perspectiva antes no reconocida y muchas veces negada. Pratt plantea que las mujeres se defirieron en diálogo con las ideas hegemónicas, reconociéndose en un lugar marginal, como mediadoras ${ }^{16}$. Las editoras hicieron esa labor de disponer de contenidos y dar sentido, tensar o discutir unos discursos que involucraban el ser de las mujeres a fin del siglo XIX. Eso lo hacían a través de la elección del formato de la publicación, la disposición de secciones regulares sobre ciertos temas, la selección de autores/as, de textos y sus contenidos, la diagramación: en el sentido de dar importancia a un discurso, entre otras decisiones.

Los periódicos y revistas fueron por antonomasia los mecanismos de difusión de las nuevas voces. Fueron la encarnación del cambio modernizador, ya que sus condiciones de posibilidad estuvieron en la modernización de la industria del papel, transportes y comunicaciones. Esto llevó a la especialización del oficio del escritor y la profesionalización de la prensa ${ }^{17}$. Aquí las mujeres, aprendiendo el oficio de editar, se hicieron profesionales de la letra y las comunicaciones, encontrando un lugar donde podían ejercer varias dimensiones del poder: para sí mismas al constituirse como sujetos y en el espacio público como mediadoras y traductoras de discursos.

12 Soledad Falabella, "Modernidad literaria y la entrada de las mujeres a la esfera pública en los discursos", Revista Chilena de Literatura, n82 (noviembre 2012), pp.125.

13 Doll, Darcie. "Desde los salones a la sala de conferencias: mujeres escritoras en el proceso de constitución del campo literario en Chile". Revista Chilena de Literatura, (71). 2007

14 Ángel Rama, opus cit.

15 Claudia Darrigrandi, Huellas de la ciudad: figuras urbanas en Buenos Aires y Santiago de Chile, 1880-1935, Santiago, Cuarto Propio, 2014, pp.20.

16 Mary Louise Pratt, "Las mujeres y el imaginario nacional en el siglo XIX", Revista de Crítica Literaria Latinoamericana, Año 19, n³8 (1993), pp.54.

${ }_{17}$ Claudia Darrigrandi, opus cit pp.20. 
A fin del siglo XIX se puede vislumbrar un decidido movimiento femenino que presionaba por el ingreso al espacio público y una evidencia fue el desarrollo de prensa. Tenemos antecedentes de prensa de y para mujeres, desde 1850. Estos son medios que reflexionan sobre el lugar de las mujeres en la sociedad. Son dirigidos o producidos por mujeres para un público de mujeres, independiente del lugar político que se ocupe, los objetivos y los temas que se aborde. Así tenemos editoras y prensa de mujeres conservadora, católica, feminista, obrera, etc. La clave es entender esta prensa como un espacio de reflexión de las propias mujeres sobre su rol social, político y cultural ${ }^{18}$.

Las decisiones de las editoras fueron clave para lograr ciertos efectos en el espacio público. Esta prensa de y para mujeres representó un movimiento moderado, aunque no exento de polémica. El formato periódico o revista fue utilizado por las mujeres para camuflar su acción como sujetos con opinión en un medio adverso ${ }^{19}$. Dentro de este movimiento, encontramos la figura definida por Carol Arcos como "la publicista". Ésta representó la consolidación de las mujeres como sujetos, y su asunción como autoras fundando un nuevo rol femenino que iba más allá de la maternidad. "La publicista" emitió opinión y diversificó sus formas discursivas ${ }^{20}$. La misma situación representa "la editora" definida también por Arcos, como una figura que ingresó al espacio público a través de revistas ilustradas, desarrolladas como empresas comerciales.

La diversidad de publicaciones periódicas que se han registrado bajo la responsabilidad de mujeres permite visualizar la flexibilidad de la que hablamos al referirnos a la editora. Podemos verla en las formas de circulación de los medios: comercial o no comercial; el formato: periódicos o revistas; los temas: prensa política, de literatura, cine, infantil o revistas femeninas. Podríamos pensar la figura de la editora como un espacio o lugar de enunciación marginal dada las normas de género, que le permite configurarse como profesional.

\section{Los discursos sociales}

El siglo XIX fue un momento clave para discutir el lugar de las mujeres en la sociedad. En el debate sobre el modelo de nación que se buscaba establecer, la naturaleza de los sexos, sus funciones, caracterizaciones y el lugar en el espacio público y privado, dieron cuerpo a una polémica intensa. El discurso de género dominante se basaba en una forma de observación de la fisiología de hombres y mujeres. Esta última determinaría la mente y capacidades de cada sexo, lo que fundamentaba una diferencia irremontable entre ellos 21 .

Las definiciones sobre ser varón o mujer eran universalistas, por lo tanto, se hablaba en singular de cada uno de ellos: era "la mujer" y "el hombre". La diferencia establecía la idea de que el hombre era un ser libre y racional, con capacidad de iniciativa, acción y reflexión. Esto le otorgaba el derecho de participar en la esfera pública en todas sus dimensiones y sus acciones se relacionaban con la producción: económica, intelectual, etc. Si bien por condiciones de raza y clase había hombres que no calificaban para ingresar al espacio público de la "Res-Pública", ningún varón era excluido de la esfera de la producción.

Por su parte, "la mujer" estaba signada por su destino biológico de la maternidad. Esto la definía atada a la naturaleza, lo que significaba que ésta controlaba su psique haciéndola sensible, dominada por

\footnotetext{
18 Montero, $Y$ también bicieron...

19 Montero, Claudia. "Trocar agujas por la pluma": las pioneras de la prensa de y para mujeres en Chile, 1860-1890. Meridional. Revista Chilena de Estudios Latinoamericanos, (7), 2016. pp. 55-81.

20 Arcos, Carol "Autorías femeninas fundacionales: escritoras chilenas y brasileñas del siglo XIX (1840-1890)", Tesis doctoral. Universidad de Chile, 2014.

${ }^{21}$ Peyrou, Florencia. "Familia y política. Masculinidad y feminidad en el discurso democrático isabelino". Historia y política núm. 25, enero-junio, 2011, págs. 149-174. p150
} 
la emociones y poseedora de una superioridad moral ${ }^{22}$. Estas características determinaban que las mujeres tenían su lugar en el espacio privado asociado a la reproducción (no en el lugar de lo íntimo que permite el desarrollo de la subjetividad). Esto significa quedar vedada del ejercicio de la reflexión y cumplir las labores de reproducir: a través de parir nuevos ciudadanos, la crianza, los cuidados generales, en fin, disponer para que otros produzcan. Frente a estas normas de género, las mujeres reaccionaron no necesariamente desde el lugar que se les asignó y pelearon por un lugar en el espacio público. En eso consistió la estrategia de editar medios de prensa. El fenómeno se hace más interesante cuando vemos que esa participación que en sí es una transgresión, implicó discursos en defensa de la norma, además de aquellos críticos.

El discurso liberal recogió la visión pre-ilustrada sobre las mujeres, que las concebía como una versión defectuosa del varón. Esto llevó a que hombres y mujeres se consideraran complementarios, dadas sus diferencias y funciones distintas, que en conjunto aportaban al bienestar de la comunidad. A pesar de ello, la igualdad de hombres y mujeres era considerada absurda y antinatural ${ }^{23}$. Un ejemplo de ello son las ideas de Sarmiento cuando se refería a la necesidad de educación de las mujeres. Para este intelectual liberal autoritario según Luis Corvalán ${ }^{24}$, ésta era fundamental para la conformación del sistema educativo a implementar en las nuevas naciones americanas. Según Sarmiento "puede juzgarse del grado de civilización de un pueblo por la posición social de las mujeres"25. Esto porque se les asigna el lugar de la formación de los nuevos ciudadanos, aunque limitado a la instrucción primaria. De tal forma sería necesaria su formación para que cumplan su labor de acuerdo a los estándares necesarios para ejercer su labor como formadoras: "cierto número de mujeres muy crecido debieran en todo caso recibir una buena educación, para servir de maestras para enseñar a los pequeñuelos los primeros rudimentos de lo que constituye la enseñanza primaria"26. En cualquier caso, tanto el rol de las mujeres en la sociedad como la defensa de su educación, no era para el desarrollo de ellas en tanto sujetos, sino en tanto piezas de un mecanismo. Es decir, cumpliendo su labor de reproducción.

Necesariamente la discusión sobre el orden de los sexos implicó la reflexión sobre la familia. Esta se entendía como la célula básica de la sociedad, donde las mujeres debían cumplir su función afectiva y formadora. Como tal, debía ser definida, ordenada y regulada por cualquier proyecto de conformación nacional, ya que en ella se transmitían los valores cívicos y morales de los futuros ciudadanos. También porque era uno de los polos que organizaba las relaciones de poder y la vida política nacional. La familia era una metáfora del imaginario nacional ${ }^{27}$.

\section{Qué dicen las editoras sobre la familia y el rol de las mujeres en la sociedad}

Respecto de los contenidos sobre la familia y el rol de las mujeres en él, existe una alta presencia en todos los tipos de medios editados por mujeres. Como dijimos, en la medida que es prensa de y para mujeres, es decir que reflexiona sobre el lugar de las mujeres en la sociedad, este tema está siempre presente. Independiente de la postura ideológica de la editora y del tipo de medio (ya sea político, cultural, comercial).

\footnotetext{
22 Lavrín, Asunción. Women, Feminism, and Social Change in Argentina, Chile, and Uruguay, 1890 - 1940. University of Nebraska Press, 1995.

23 Peyrou, opus cit. P 151

${ }^{24}$ Luis Corvalán, "Los inicios de la corriente civilizatoria", en Ensayos sobre la lucha por un pensamiento propio en nuestra América, Santiago, Editoria América en movimiento, 2015, p 30.

25 Domingo Sarmiento, "De la educación de las mujeres", en De la educación Popular. Santiago, Imprenta de Julio Belin y Compañía, $1849, \mathrm{p} 70$.

26 IBIDEM.

${ }^{27}$ Peyrou, opus cit. P 151
} 
Para fin del siglo XIX revisamos tres medios: El Eco de las señoras de Santiago (1865), La Brisa de Chile (1876) y La Familia (1891-1894). Los tres representan distintos tipos de medios: El Eco es un periódico político, la Brisa de Chile es una revista literaria y La Familia una revista magazinesca comercial.

Como es propio de la prensa de mujeres de fin del siglo XIX en Chile, éstos medios fueron producidos por mujeres de la elite intelectual y económica del país. Si bien El Eco de las Señoras de Santiago es anónimo, desde un inicio su autoría ha levantado polémica. Por una parte existen las posturas que plantean que independiente del género de sus productores/as el hecho de poner a las mujeres en el lugar de enunciación es un cambio y la inauguración de las mujeres como sujetos capaces de emitir opinión ${ }^{28}$. Una segunda postura plantea que la autoría del periódico fue masculina ${ }^{29}$. Este fue un periódico político surgido en el contexto del debate por la libertad de culto y la relación entre Estado y religión. Su objetivo era criticar la reforma que quería suprimir la exclusividad de la religión católica. Incluyó artículos, cartas y comentarios jurídicos que expresaban la opinión de las productoras respecto de la controversia: defender la religión católica como religión de Estado. Además, publicó textos de moral cristiana y otros que definían el ideal femenino conservador. Tanto su formato, como el contenido de sus textos, los elementos complementarios como avisos y otros, nos hablan de mujeres que comienzan a ser tanto productoras como público, independiente del género que esconde el anonimato del periódico.

El ideal conservador que formaba parte de la línea editorial del Eco reprodujo un ideal femenino acorde con las normas de género de la época, es decir, una mujer que representaba el ideal del ángel del hogar. Debía volcar toda su capacidad de acción en el espacio doméstico, donde debía cumplir su función social fundamental que era conservar la familia. Ese es el argumento que se expone en el número 1 del periódico para invitar a las lectoras a leer y participar con colaboraciones:

De mucho tiempo atrás deseábamos publicar un periódico que fuese órgano fiel de nuestra ideas y sentimientos. Conviene en gran medida que nos ilustremos recíprocamente sobre muchos asuntos de grande interés para nosotras. La educación y cuidado de nuestros hijos, el ejercicio encantador de las obras de misericordia en todas su ramificaciones, etc., son materias sobre las cuales será muy útil nos transmitamos las nociones que más se armonicen con nuestro estado social, y que afiancen más la felicidad de las familias y de la patria ${ }^{30}$.

Las editoras del Eco asumían la norma de género que implicaba que todo el peso de la educación moral de la sociedad recaía en las mujeres, quienes en tanto madres y temerosas de Dios, debían formar los valores de los ciudadanos del futuro. Fue un tema recurrente en el periódico la expresión de temor de las madres frente al posible colapso social que significaría la laicización de las leyes, como se expresa en el poema "El Porvenir de mis hijos":

"El mal su imperio extiende

Sobre la patria mía,

¡Tristes los espíritus

Se postran con dolor!

¿Dios, cómo permites

que la maldad impía

Recorra nuestro suelo

Sembrando destrucción? [...]

\footnotetext{
28 Stuven, Ana María. "El Eco de las Señoras de Santiago de 1865. El surgimiento de una opinión pública femenina", Lo público y lo privado en la historia americana, Santiago, Fundación Mario Góngora, 2000 pp 303 - 327.

${ }^{29}$ Ramirez et.al. Antología Crítica de las mujeres en la prensa chilena del siglo XIX. Santiago, Cuarto Propio, 2017

30 "Una invitación", El Eco de las señoras de Santiago, Año I, número 1, 13 de julio 1865, Santiago, 1.
} 
Velad, o madres tiernas, Velad por vuestros hijos, No se que en sus almas Impere la impiedad!

Tened en ellos, madres

Los pensamientos fijos

Guardad su corazones!...

Por ellos implorad!" 31

En la función de la maternidad no había lugar para el padre. Sin embargo, este ideal estaba lejos de ser encarnado por mujeres débiles o inactivas. Hay cierta tensión en el discurso, porque suponía mujeres fuertes en términos morales, con un poder que se lo daba la superioridad moral que le permitía guiar las vidas de las personas que estaban a su cargo.

Nos habéis declarado inhábiles para elegir a los representantes de la nación y por más desastrosas que sea esta declaración, la aceptamos con gusto y aun la justificamos. Nos habéis excluido de los Congresos, y aplaudimos vuestra determinación. Pero no habéis sellado nuestros labios, ni podéis sellarlos, y hablaremos. Tenemos derecho para escribir, y escribiremos. Si, vamos a defender las instituciones amagadas, los derechos religiosos violados el decoro de la patria mancillado. Y Chile verá que las hijas de su escogido suelo saben trocar las agujas por la pluma: Y se solazan más en escribir en defensa de la ventura patria, que en arrancar al piano embriagantes melodías ${ }^{32}$.

Estas ideas fueron sustentadas por las decisiones editoriales de las mujeres que estaban a cargo del periódico. Como se mencionó este fue un periódico político donde abundaban los textos de defensa del statu quo frente a las reformas políticas que se venían. El ideal de mujer madre que se proponía se planteaba en diversos tipos de textos, de autoría masculina o femenina, sobre la labor de la mujer en la sociedad. En este sentido se entiende la decisión editorial de incluir textos como "La Mujer", ensayo del padre Ventura de Raulna incluido en el número 1 del periódico donde plantea que mientras el hombre es más fuerte que la mujer en el orden físico, la mujer es más fuerte que el hombre en el orden moral, ámbito en el que la mujer ejerce un inmenso poder sobre el hombre.

Admirable designio del creador el haber formado a la mujer más fuerte que al hombre en el orden moral, y al hombre más fuerte que la mujer en el orden físico. El poder de la mujer sobre el hombre, para el bien y para el mal, señalado por la escritura. La manera bárbara con la mujer es tratada.

Los seres que forman la familia, lo mismo que los forman el estado y los que forman el universo, no pueden llenar sus funciones ni conseguir su fin sino en tanto que el orden existe entre ellos, y el orden no puede existir entre ellos sino por el equilibrio de las fuerzas y de los poderes. Era pues necesario que el hombre y la mujer, seres de la misma naturaleza y de la misma especie, pero tan diferentes el uno del otro por sus cualidades y sus condiciones, pudiesen equilibrarse y armonizarse entre sí. Esto fue lo que hizo la sabiduría del creador al forma a la mujer tanto más poderosa que el hombre por sus atractivos y sus gracias, cuanto el hombre es más poderoso que ella por la fuerza y la autoridad".33

\footnotetext{
31 Una Madre. "El Porvenir de mis hijos". "El Eco de las Señoras de Santiago". Periódico semanal Año I, número 2, 20 de julio 1865, Santiago de Chile.

32 "A nuestras compatriotas", El Eco de las señoras de Santiago, Año I, número 1, 13 de julio 1865, Santiago, 1.

33 Ventura de Raulna. "La Mujer” El Eco de las señoras de Santiago, Año I, número 1, 13 de julio 1865, Santiago, 1.
} 
Los tres textos citados son muy distintos entre sí tanto en tono como en contenido, considerando, además, que uno de ellos es de evidente autoría masculina. Esto habla desde los distintos lugares ocupaban las mujeres, independientemente de que la norma de género fuera el mismo: reproducción. Tenemos en el poema una mujer que asume un lugar secundario en la toma de decisiones política, donde le queda nada más que rezar por el bienestar de sus hijos, que es su responsabilidad. Otro donde las mujeres asumen un lugar de poder dada su clase social y la superioridad moral que tenían en tanto mujeres, para demandar políticamente, y un tercero que reflexiona sobre el rol de las mujeres, reforzando patrones tradicionales. Por otra parte, se puede ver la decisión editorial de unir tanto la demanda política del periódico con el ideal de maternidad que divulgaba. Por lo tanto, lo que vemos es una madre que no sólo debe reproducir la vida doméstica, sino que debe tener una opinión frente a la vida política.

Este fenómeno es interesante, ya que evidencia una tensión del ideal de domesticidad femenino que representa la propia publicación del periódico. Si las mujeres no debían opinar públicamente, si las mujeres debían reproducir la vida en lo doméstico ¿cómo se explica que éstas mujeres que defendían ese ideal lo transgredieran para opinar sobre un asunto de política nacional? ¿es que el tema defendido, la defensa de la tradición, les autorizaba a salir a la luz pública y traspasar el límite que se suponía defendían? ¿cómo se puede encarnar a la madre temerosa de Dios, obediente y sumisa, y a la vez tener el poder moral que le permite emitir opinión política para formar a los ciudadanos que se espera?

Esta tensión es muestra de una decisión editorial femenina. Ya que es un ideal femenino como ángel del hogar con poder, que representa a las mujeres de clase alta que son tanto las que editan el periódico, como el público al que lo dirigen.

...Pero esa ocasión ha llegado, y fuerza es manifestarse dignas hijas de Chile.

No es sólo dando pan al menesteroso como hemos de trabajar en bien de la patria, sino también enseñando al ignorante, rectificando los errados conceptos que vagan confusos en la sociedad. Cada época tiene sus caracteres especiales: el periodismo es hoy la palanca que mueve al mundo, el telégrafo que habla a todas partes, y al periodismo acudimos nosotras.

Además del bien público, el honor de señoras está empeñado en llevar adelante esta publicación. No se diga en ningún tiempo que las hijas de Chile sintieron crujir la tempestad y se escondieron; que habiendo podido detener el carro revolucionaros se retiraron cobardes a embriagar sus corazones en las danzas y en los conciertos y dejaron que la patria se hundiera en los abismos. ¡Pues bien, señoras chilenas! Estrechemos más nuestros vínculos patrios. Todas tenemos un mismo interés, un mismo pensamiento: la prosperidad de Chile. Tengamos también todas una misma voz"34

La clase social de las editoras marca un ideal de domesticidad que lo tuerce para extender hacia lo público la labor de cuidado y formación moral que supone debe hacer la madre en el hogar. Una estrategia de difusión de este ideal fue a través de cuentos como: "El memorial del ángel de la guarda", "Una lección maternal", que a través de metáforas representan las acciones que la madre debía hacer para cumplir su función en la familia.

Otro ejemplo es el periódico La Brisa de Chile (San Felipe 1875) editado por Lucrecia Undurraga. Este fue un periódico que se definió como literario, de regularidad semanal durante dos años. Su objetivo era mejorar la educación de la mujer. Su editora, Lucrecia Undurraga fue hija de una familia acomodada de provincia que accedió a educación en colegios públicos. Se casó con un empresario de la minería del que enviudó joven. Ello le permitió heredar propiedades comerciales con las que pudo sostenerse y dedicarse completamente a su vocación literaria ${ }^{35}$. Lucrecia Undurraga fue una escritora profesional cuya

34 “Una invitación”, El Eco de las señoras de Santiago, Año I, número 1, 13 de julio 1865, Santiago, 1.

35 Ulloa, Carla. "Lucrecia Undurraga y el periodismo liberal de mujeres en el Chile decimonónico: La Brisa de Chile (1875-1876) y La Mujer (1877)." En Escritoras chilenas del XIX. Su incorporación pionera a la esfera pública y al campo cultural, Damaris Landeron, Joyce Contreras y Carla Ulloa. Santiago, RIL, 2017. 
obra abarcó ensayos, discursos, obras teatrales, cuentos y artículos periodísticos. Como editora publicó La Brisa de Chile y La Mujer (1877). Su postura política era liberal y progresista coherente con ideas sobre la emancipación femenina.

Las decisiones editoriales de Lucrecia Undurraga respecto de la reflexión de las mujeres en la sociedad y la familia, incluyeron la incorporación de ensayos sobre temas como la labor de la madre, la educación moral de la juventud o sobre la educación de la mujer. Al igual que en el periódico desarrollado por mujeres conservadoras, en éste se defendía el ideal de mujer tradicional como ángel del hogar. Desde allí la función más importante de las mujeres era la de educar y ser el pilar de la familia. Una diferencia con el medio conservador, es que las autoras de los textos incluidos en La Brisa de Chile, son en su totalidad de autoría femenina. La decisión editorial implicaba poner en valor la voz y opinión de mujeres sobre las propias mujeres. En el texto de Enrique Corbis "Educación moral de la juventud", la autora plantea que esta es "una materia delicada", y por lo tanto se dirige a las madres que están a cargo de la formación de los hijos:

A vosotras, pues, honorables madres de familia, me dirijo; pues que sois el ángel tutelar de la inocencia y el digno artífice que debe formar moralmente el corazón de sus tiernos hijos. [...] Vigilad constantemente las pasioncillas que se despiertan en el alma de esos seres queridos que os confío el Padre común y enderezadlas desde temprano: el árbol que crece bajo el cuidado del hábil hortelano medrará en breve y fácilmente lo enderezará si no fuere recto $[\ldots]$ ¡Oh, dignas madres de familia! formad el corazón de vuestros hijos en la sólida piedad, en la práctica de las virtudes morales y sociales y habréis hecho un bien inapreciable ${ }^{36}$.

Si bien el ideal femenino defendido por la línea editorial liberal de La Brisa de Chile a cargo de Undurraga, fue el de ángel del hogar, y por lo tanto sostén de la familia en tanto reserva moral, la diferencia con el discurso conservador está en el énfasis que se da a la educación de las mujeres. Que las mujeres fueran el sostén familiar justificaba la inversión en educación pública para mujeres pobres. Este discurso incluía a mujeres de todas las clases sociales. El empoderamiento de las mujeres no recaía en su capacidad de acción política en tanto mujeres de la elite económica (como en el caso de las editoras del Eco), sino en su condición de ser madres de las distintas clases sociales para influir en la formación ciudadana. Por ejemplo, en el texto "La Agonía de una madre", se expone la historia de una modesta y anciana mujer al borde de la muerte quien aconseja a su hija, "la desdichada Amalia", "que ya no recibirá sobre su frente virginal el beso de amor del ser que le dio la vida". Durante la noche de desvelo la madre, ante la proximidad de la separación, le dice a su hija:

El orgullo es una de las pasiones más innobles de la mujer; el orgullo degrada, no realza; envilece no eleva. Desprecia, pues, el lujo, desprécialo, Amalia: que, si el lujo obtiene un triunfo pasajero, ese triunfo es casi siempre precursor de la más triste deshonra y de la más afrentosa ignominia. [...] No ambiciones riquezas sino para distribuirlas entre los pobres. No busques la felicidad en el bullicio del mundo, sino en el retiro del hogar; no lo busques en los placeres fugaces de esta sociedad escéptica, sino en la práctica del bien i en el culto hermoso de la virtud ${ }^{37}$.

En este texto se reflexiona sobre las lecciones que da la madre moribunda a su hija, haciendo alusión a las mujeres de clase alta. La instrucción de alejarse del lujo es una crítica a la sociedad excluyente defendida por la oligarquía criolla. Por su parte, a las mujeres de las clases populares se las reconoce como

\footnotetext{
36 Courobis, Enriqueta. "Educación moral de la juventud". La Brisa de Chile. Periódico literario de la juventud. Literatura, ciencias, artes, modas, música, variedades. Año 1, núm. 4, 16 de enero de 1876, San Felipe. p.25

37 Anónimo, "La agonía de una madre". La Brisa de Chile. Periódico literario de la juventud. Literatura, ciencias, artes, modas, música, variedades. Año 1, núm. 3, 9 de enero de 1876, San Felipe. pp.20-21
} 
el sostén de la familia, sin presencia del padre, y por lo tanto la base de la sociedad y en función de ello se defiende la educación para las mujeres.

La educación de las mujeres sería necesaria para equilibrar la desigualdad social a la que se está sometida en tanto mujer. En esta demanda hay una profunda crítica al sistema patriarcal que sería el causante de la condición desmedrada de las mujeres. Esto se puede ver en el texto de Eduvijis C. De Polanco "Reflexiones. Sobre la educación pública de la mujer en Chile"38, dedicado a don Francisco Echaurren presidente de la Comisión Visitadora de las Escuelas de Niñas.

La autora, antes de entrar de lleno en el origen de las escuelas públicas de niñas, considera necesario hablar sobre "la historia de los destinos de la mujer y a su condición moral, durante los siglos que precedieron a la aparición del Cristianismo". Es así que dibuja el destino de la mujer "en aquellas edades" donde "no se le dió(sic) a la mujer un solo privilegio; nada se hizo por sacarla de la ignorancia y de la miseria; nada por su conveniencia y dignidad; se le exigía, sin embargo, la más completa abnegación, poner su alma y su cuerpo al servicio de su señor". Con el paso del tiempo "la mujer principió a imitar al hombre en el raciocinio; buscó el modo de hacer valer lo que nadie podía quitarle; se valió de sus gracias personales y de su hermosura y entonces apareció en el mundo la seducción. En ésta estrivó(sic) su fuerza". Pero ese triunfo fue efímero, como relata la autora, el trato de diosa y el estatus de sacerdotisa duraban poco, pues se acababa, "apenas se marchitaba sus atractivos". Esa fue el destino de la mujer durante el paganismo, "pasan los siglos, y la mujer siempre vendida y esclava, deja una servidumbre por otra".

Por otro lado, el cristianismo, "exalta a la mujer, la purifica y la levanta a la altura del hombre". Su entendimiento antes ofuscado, ahora con el cristianismo se engrandece, ha visto el verdadero tipo de mujer, con virtud y encanto infinitos "en la juventud con su inocencia, en la edad madura con su prudencia y buen juicio y en la ancianidad con la ciencia que da la práctica de todas las virtudes y la calma de quien ha llegado una vida sin mancilla", sin embargo, hubo mujeres que se mantuvieron en las sombras, las que han llevado una vida de pasiones y vicios, "aquellas que no llevan sino el nombre de cristianas, quizá no hubieran sucumbido si se las hubiese instruido en tiempo de sus deberes". En vista de que estas mujeres, las que no recibieron una instrucción cristiana, se pensó "en educar a las pobres, en llevar hasta las que se llaman hoy mujeres del pueblo los beneficios de la instrucción y buena educación". Esta es la razón de la creación de las escuelas gratuitas para niñas, en vista de que la mujer es la base o centro moral de la familia "los pueblos, se empeñaron de día en día, y con justísima razón, en educar mejor a la mujer".

En la Brisa de Chile, la editora muestra la tensión de la discusión sobre la capacidad de ser sujeto social de las mujeres. Por una parte, los textos tienen en su base la idea liberal de la mujer como complemento del hombre y por lo tanto con una función específica: la reproducción. Esto implica que tiene una labor fundamental para la sociedad, pero en segundo plano, que no le permite acceder a la discusión en el espacio público. Con ese argumento se demanda educación como en este poema de Rosario Orrego:

"Instruid a la mujer, si queréis pueblos

Que se eleven felices, soberanos. [...]

Si es instruida i virtuosa ántes que bella, Allí habrá dicha, libertad, unión. [...] Sensible, amante, generosa, ingenua, Escollos mil encuentra en su camino, ¿Y cómo ha de luchar contra el destino Si no adquiere la ciencia del vivir? [...]

38 Eduvijis C. de Polanco. "Reflexiones. Sobre la educación pública de la mujer en Chile. (I)". La Brisa de Chile. Periódico literario de la juventud. Literatura, ciencias, artes, modas, música, variedades. Año 1, núm. 5, 23 de enero de 1876, San Felipe. p. 35-38 
Pues ¿qué le sirve frágil hermosura, Flor que deshoja el hálito del viento, Si no brilla en su frente un pensamiento Que revele su origen celestial? [...] $¿ \mathrm{Si}$ abandona su rica inteligencia Bajo el ocio fatal que la domina, Si no estudia, no piensa, no imagina Más allá de lo frívolo y trivial? Mostradle el vasto campo del estudio, Premiad con noble aplauso su desvelo, Y amante inteligente, os dará un cielo, Dando al hogar la dicha i el amor"39.

La tensión que evidencia la editora La Brisa de Chile está en que junto con la idea liberal de que las mujeres serían complemento del hombre, son también capaces de desarrollar una subjetividad en sí misma. Esto se ve en el tono de advertencia que poseen muchos de los textos, donde el sujeto al que se le habla son las propias mujeres jóvenes, para alertarlas a que se cultiven a sí mismas. Tanto es así que, en el entusiasmo de la celebración de dos meses de publicación ininterrumpida, en el número 7 , se menciona la emancipación:

Se abren anchos horizontes; principia una era nueva para la mujer, asoma la aurora de la emancipación. La Brisa de Chile anuncia el elevado propósito de educarla, de ilustrarla, de rejenerarla, en fin. ¡Salud a esa nueva aurora que ilumina los Andes!

Hijas de Aconcagua asociémonos a tan noble tarea unámonos a un mismo pensamiento. Cultivemos las letras y ellas serán el faro que nos señalen los escollos en las borrascas de la vida, el arca santa a donde iremos a buscar un refugio que nos salve de nosotras mismas cuando nos veamos asaltadas por el debate de las pasiones, cuando nos hallemos abrumadas por el cansancio, el hastío y las decepciones ${ }^{40}$.

En este texto se ven gérmenes de un discurso que posiciona a las mujeres como sujetos críticos al orden patriarcal. Capaces de buscar un camino propio, aunque ello no significa necesariamente realizar una transgresión completa.

Un tercer ejemplo es la revista La Familia (1890-1892) editada por Celeste Lassabe. Esta se definió como periódico, aunque corresponde al formato revista ilustrada, una de las primeras en Chile. Tuvo una circulación comercial, como producto dirigido a las dueñas de casa de la elite. Su objetivo fue entretener y entregar información útil para desempeñarse bien en el espacio doméstico y en la ciudad moderna. Su editora, Celeste Lassabe fue una mujer originaria de Francia perteneciente a una familia aristocrática. Se vino a Chile con su primer marido que venía a hacer negocios al país. Enviudó muy joven. Sin embargo, no quiso volver a Francia. Se instaló en Valparaíso, la ciudad cosmopolita de fin del siglo XIX. Se casó por segunda vez con un hombre con el que compartió la pasión por las letras, el arte y el desarrollo del periodismo, formando parte del círculo intelectual de la ciudad puerto. Así Celeste Lassabe se convirtió en salonier y se consolidó como escritora al ser la segunda mujer en publicar una novela en Chile ${ }^{41}$. Lo hizo en su propia revista, en formato folletín.

39 Orrego, Rosario. "La Mujer. Poesía leída en la Academia de Bellas Letras". La Brisa de Chile. Periódico literario de la juventud. Literatura, ciencias, artes, modas, música, variedades. Año 1, núm. 3, 9 de enero de 1876, San Felipe. pp.19-20

40 Solar, Enriqueta. "Brisa del norte". La Brisa de Chile. Periódico literario de la juventud. Literatura, ciencias, artes, modas, música, variedades. Año 1, núm. 7, 6 de febrero de 1876, San Felipe. p. 52

${ }^{41}$ Cruz-Coke, Marta. Eduardo Cruz-Coke. Testimonios. Santiago, Fundación Procultura, 2015. 
En relación con los discursos sobre la familia y las mujeres, Celeste Lassabe incluyeron decisiones editoriales de modo de instalar sus ideas dentro del formato revista ilustrada. Esto implicó la inclusión de secciones regulares que reforzaban el ideal de ángel del hogar. Por ejemplo, está: "Economía doméstica" desde el número 1, "Manual para la dueña de casa" desde el número 2, "Procedimientos útiles" a partir del número 6, "El Hogar doméstico" desde número 6, "La educación del Nene", desde el número 13. En este sentido no fue distinta a los otros ejemplos que vimos con el periódico político y la revista literaria. En los tres casos la domesticidad de las mujeres era un valor a rescatar y reproducir. Más aún en esta revista cuyo nombre da cuenta de la relación entre mujer y lo doméstico: La Familia. En relación con este punto, Celeste Lassabe fue una pionera. Ya que emprendió esta empresa con un objetivo comercial. Es decir, esperaba ganancias de ello, a diferencia de los ejemplos anteriores, cuyo objetivo programático (en un caso cultural y otro político) hacía que su supervivencia estuviera acotada a cumplirlo ${ }^{42}$.

En el caso de La Familia, Lassabe como editora encuentra un público específico: mujeres de elite a cargo de sus hogares como jefas de familia (en tanto ángeles del hogar). Dentro de una incipiente sociedad de consumo, crea un producto para ellas. Supo entender el espíritu aristocratizante de la belle epoque criolla, ofreciendo un periódico que funcionaba como catalizador en una nueva sociedad urbana: era producto de una nueva forma de habitar la ciudad, y a la vez enseñaba los códigos de comportamiento para salir airosa en ella, y cómo ser la representante ideal de una familia moderna ${ }^{43}$.

Estos ideales se evidenciaron no sólo en los textos seleccionados para publicar, sino en las secciones que articularon la revista. Ejemplo de ello fue el "Manual de la Dueña de Casa" de Emmeline Raymond, que aparecía regularmente en cada número. En ella se enseñaba cómo organizar el hogar, desde la contabilidad de los gastos hogareños, la forma de dirigir al personal de servicio, cómo llevar la ropa de la casa, atender a los invitados, entre muchos otros temas. En el primero de ellos inicia con las indicaciones de la contabilidad. Para ello la dueña de casa debe llevar un libro de cuentas donde anote los gastos hechos por la cocinera, y si tiene mozo de cámara, un libro aparte para los gastos que hace este. "La dueña de casa arreglara sus cuentas con los criados dos veces por semana, á lo menos, en días fijos" 44 . Y un tercer libro para los gastos personales, y por último un cuarto libro, "el libro mayor" donde anotará las entradas y la suma de los gastos de cada mes. Aconseja no mantener deudas y pagar en el acto. "El primero é invariable principio de una dueña de casa, deseosa de administra bien su reino, debe ser no comprar nunca al crédito" 45 . Continúa aconsejando con la necesidad de tener una metodología para ejecutar el trabajo, "establezco como la base del método la costumbre de no postergar nada hasta el último momento" 46 .

Otra sección era de "Economía Doméstica", también constante en cada número, donde se publicaban recetas de cocina, todas ellas sofisticadas y que representaban un menú completo de acuerdo a estándares internacionales. Por ejemplo, en el número 18 de la revista, la sección publica las recetar para "Tripas a la moda de Caen", "entremeses con crema y castañas", "pasteles merengues á la vainilla" y "pancito de la abuela".

Una tercera sección fue "La Educación del Nene". En esta se enseñaba la crianza de los hijos. No tenía relación con puericultura, sino con educación para el buen comportamiento de los niños en sus distintas etapas vitales, para adecuarse a la sociedad. En ésta última sección llama la atención que muchas veces se incluye como receptor del mensaje a "los padres". En el número 23 de la revista la autora habla del ejemplo de las personas que rodean al nene, sus padres, la familia y los sirvientes, los padres deben cuidar de dar un buen ejemplo, para que el nene por imitación no "contraiga defectos y vicios". Visto

42 Montero. Y también bicieron periódicos...

43 Montero. "Trocar las pumas..."

44 Raymond, Emmeline. "Manual de la Dueña de Casa". La Familia. Periódico Quincenal Ilustrado, de literatura, ciencias, artes, modas $i$ conocimientos útiles. Año I, número 2, 1 de septiembre de 1890, Santiago de Chile p.10

45 Ibidem

${ }^{46}$ Ibidem 
desde la actualidad podemos suponer que esto considera tanto a padre o madre. Sin embargo, no tenemos antecedentes para afirmar tal ideal. Como podemos ver en esta revista el ideal de maternidad reproduce la idea del ángel del hogar, donde la mujer adquiere el poder de administradora de la unidad familiar. Una familia moderna, donde la mujer adquiere un protagonismo más allá de la administración del personal, sino que también supone una acción directa en algunas de las actividades domésticas.

\section{Conclusión}

En este trabajo hemos tratado de poner de relieve la figura de la editora como un elemento de influencia en la circulación de discursos relativos al rol de las mujeres en la sociedad. Este fenómeno cobra importancia en un momento crítico que es la modernización donde se desarrollan una serie de transformaciones políticas sociales y culturales. Por una parte, tenemos la emergencia de nuevos sistemas comunicativos, donde las publicaciones periódicas adquieren un peso importante. Por otra parte, las mujeres comienzan a presionar por ser reconocidas como sujetos sociales con capacidad de influir en el espacio público. Es en la intersección de ambos factores donde la editora cobra peso: surgen mujeres que son capaces de transgredir el mandato social de silencio y pasividad y comienzan a desarrollar empresas culturales y políticas a través de la prensa.

Una vez en el lugar que se abrieron, se transforman en mediadoras, tomando decisiones editoriales que impactan en el espacio público. De tal forma, resulta interesante ver la tensión que representa una mujer transgresora de las normas de género, reproduciendo un discurso que refuerza un ideal de domesticidad. En el acto de tomar la palabra se abren los efectos políticos: la posibilidad de que las mujeres sean sujetos de derecho y, por lo tanto, capaces de intervenir en el espacio público.

Por lo tanto, la revisión que hicimos de los tres ejemplos presentados, nos muestra que esa reproducción de discurso no fue plana, sino que tuvo sinuosidades expresadas en la selección de contenidos realizadas por las editoras.

Si bien en los tres ejemplos el ideal de ángel del hogar pone a las mujeres como cabeza de la familia, en relación con la reproducción de la vida, existen diferencias dependiendo del lugar político y social desde el que hablan las editoras. Por una parte, tenemos a las mujeres conservadoras que defienden ser ángeles del hogar que les otorga superioridad moral que las lleva a reclamar poder político para defender unas ideas determinadas. Por otro lado, tenemos a una editora liberal que defiende el ideal de ángel del hogar de forma diferenciada, considerando la demanda por educación para las mujeres para que consigan desarrollo personal, en una crítica profunda a la sociedad patriarcal. En tercer lugar, tenemos a una editora de un producto comercial que se sirve de este ideal para obtener ganancia económica creando un producto para mujeres como jefas de familia.

El lugar que se construyeron las editoras fue un lugar de poder para disputar un lugar en el espacio público. Es un lugar de poder en la medida que crean un dispositivo para ingresar a la discusión de los asuntos públicos. En la estructura de ese dispositivo tiene el lugar de la toma de decisión para poner en juego proyectos políticos que hablan a través de contenidos, formatos y diseño de medios de prensa. Esto hace aparecer a las mujeres como sujetos políticos con capacidad de emitir opinión.

\section{Bibliografía}

Arcos, Carol "Autorías femeninas fundacionales: escritoras chilenas y brasileñas del siglo XIX (18401890)", Tesis doctoral. Universidad de Chile, 2014.

Berman, Marshall. "Brindis por la modernidad." En El debate Modernidad/Posmodernidad, Nicolás Casullo, 67-91. El Cielo por asalto, 1994. 
Claudia Darrigrandi, Huellas de la ciudad: figuras urbanas en Buenos Aires y Santiago de Chile, 1880-1935, Santiago: Cuarto Propio, 2014.

Cruz-Coke, Marta. Eduardo Cruz-Coke. Testimonios. Santiago, Fundación Procultura, 2015.

Doll, Darcie. "Desde los salones a la sala de conferencias: mujeres escritoras en el proceso de constitución del campo literario en Chile". Revista Chilena de Literatura, (71). 2007

Domingo Sarmiento, "De la educación de las mujeres", en De la educación Popular. Santiago, Imprenta de Julio Belin y Compañía, 1849.

Fraser, Nancy. "Repensando la esfera pública: una contribución a la crítica de la democracia actualmente existente." In Habermas and the Public Sphere, by Craig Calhoun. Cambridge, Massachussets, MIT Press, 1992.

Habermas, Jurgen. Historia y Crítica de la opinión pública. Barcelona, GG, 1981.

Landes, Joan. Women and The Public Sphere in the Age if the French Revolution. New York: Cornell University Press, 1988.

Lavrín, Asunción. Women, Feminism, and Social Change in Argentina, Chile, and Uruguay, 1890 - 1940. University of Nebraska Press, 1995.

Lobato, Mirta. La prensa obrera. Buenos Aires y Montevideo 1890-1958. Buenos Aires, Edhasa, 2009.

Luce Irigaray, El cuerpo a cuerpo con la madre, Barcelona, Lasal, 1985.

Luis Corvalán, "Los inicios de la corriente civilizatoria", en Ensayos sobre la lucha por un pensamiento propio en nuestra América, Santiago, Editoria América en movimiento, 2015.

Mary Louise Pratt, "Las mujeres y el imaginario nacional en el siglo XIX", Revista de Crítica Literaria Latinoamericana, Año 19, n³8, 1993

Montero, Claudia. "Trocar agujas por la pluma": las pioneras de la prensa de y para mujeres en Chile, 1860-1890. Meridional. Revista Chilena de Estudios Latinoamericanos, (7), 2016. pp. 55-81.

Montero, Claudia. Y También bicieron periódicos... Cien años de prensa de mujeres en Chile 1850-1950. Santiago, Hueders, 2018.

Peyrou, Florencia. "Familia y política. Masculinidad y feminidad en el discurso democrático isabelino". Historia y política núm. 25, enero-junio, 2011, págs. 149-174.

Rama, Ángel. La ciudad letrada. Montevideo, Arca, 1998.

Ramírez et.al. Antología Crítica de las mujeres en la prensa chilena del siglo XIX. Santiago, Cuarto Propio, 2017. Scott, Joan. "El Género: una categoría útil para el análisis histórico." In El Género: la construcción cultural de la diferencia sexual, by Marta Lamas. México D.F, UNAM, 1996.

Scott, Joan. "Género: ¿'Todavía una categoría útil para el análisis?”. La Manzana de la Discordia, [S.l.], v. 6, n. 1, p. 95-101, mar. 2016. ISSN 2500-6738.

Soledad Falabella, "Modernidad literaria y la entrada de las mujeres a la esfera pública en los discursos", Revista Chilena de Literatura, n82, noviembre 2012.

Stuven, Ana María. "El Eco de las Señoras de Santiago de 1865. El surgimiento de una opinión pública femenina", Lo público y lo privado en la historia americana, Santiago, Fundación Mario Góngora, 2000 pp $303-327$.

Ulloa, Carla. "Lucrecia Undurraga y el periodismo liberal de mujeres en el Chile decimonónico: La Brisa de Chile (1875-1876) y La Mujer (1877)." En Escritoras chilenas del XIX. Su incorporación pionera a la esfera pública y al campo cultural, Damaris Landeron, Joyce Contreras and Carla Ulloa. Santiago, RIL, 2017. 